\title{
Th-U (Thorium-Uranium)
}

\author{
H. Okamoto
}

The Th-U phase diagram in [Masslski2] was redrawn from [1985Pet], which was based on experimental phase boundary data reported by [1950Car], [1958Ben], [1958Mur], and [1972Bad]. Figure 1 shows the Th-U phase diagram calculated by [2009Li] based on the same data set as used in the evaluation by [1985Pet].

Earlier, [1980Cha] obtained the Th-U phase diagram of a simple eutectic type with no miscibility gap in the liquid phase by thermodynamic modeling. The existence of the miscibility gap with the peak at $1555{ }^{\circ} \mathrm{C}$ was reported by [1972Ack] also. Therefore, the existence of the miscibility gap seems to be real and the thermodynamic model of [1980Cha] may be in need of further refinement.

\section{References}

1950Car O.N. Carlson, Some Studies on the Uranium-ThoriumZirconium Ternary Alloy System, USAEC Report AECU3206, 1950
1958Ben G.G. Bentle, Study of the Thorium Alloy Systems, Proceedings of the UN International Conference on the Peaceful Uses of Atomic Energy (Geneva), 1958, Vol 6, p 61-156

1958Mur J.R. Murray, The Uranium-Thorium System and Some Aspects of the Uranium-Thorium-Zirconium Alloy System, J. Inst. Met., 1958-1959, 87, p 94-96

1972Ack R.J. Ackermann and E.G. Rauh, Determination of Liquidus Curves for the Th-W, Th-Ta, Zr-W, and Hf-W Systems: The Anomalous Behavior of Metallic Thorium, High Temp. Sci., 1972, 4, p 272-282

1972Bad T.A. Badayeva and R.I. Kuznetsova, Solidus and Liquidus Surfaces of the Th-Zr-U Phase Diagram, Izv. Akad. Nauk SSSR, Met., 1972, (1), p 196-199, in Russian; TR: Russ. Metall., 1972, (1), p 139-142

1980Cha K.S. Chan, J.K. Lee, and H.I. Aaronson, Kaufman Approach Calculations of Partial Phase Diagrams Amongst Th, U, Np, and Pu, J. Nucl. Mater., 1980, 92, p 237-242

1985Pet D.E. Peterson, The Th-U (Thorium-Uranium) System, Bull. Alloy Phase Diagr., 1985, 6(5), p 443-445

2009Li Z.S. Li, X.J. Liu, and C.P. Wang, Thermodynamic Modeling of the Th-U, Th-Zr, and Th-U-Zr Systems, J. Alloys Compd., 2009, 476, p 193-198

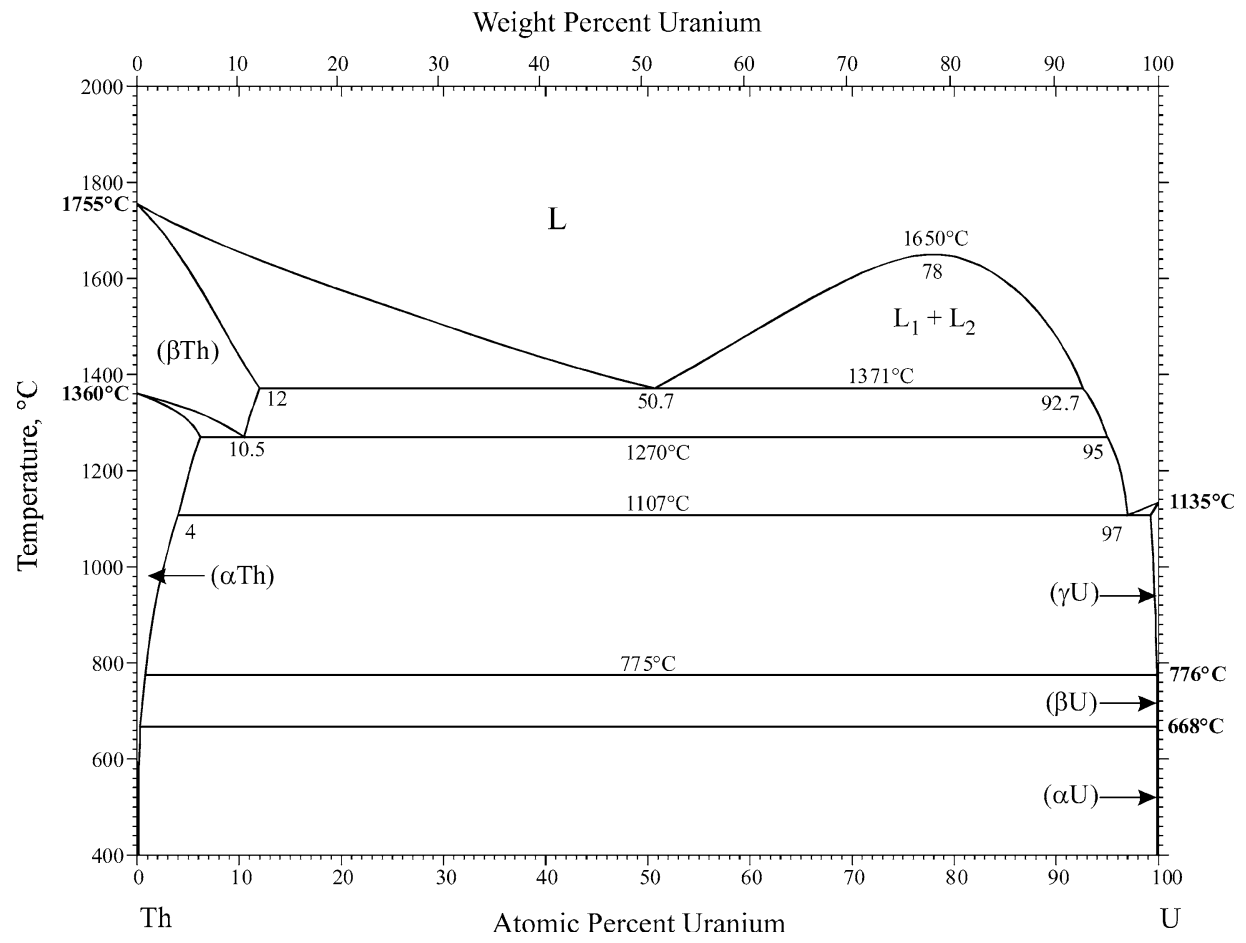

Fig. 1 Th-U phase diagram 